\title{
Broader horizons for animal personality research
}

\section{Sonja E. Koski*}

Anthropological Institute and Museum, University of Zürich, Zürich, Switzerland

\section{Edited by:}

James A. R. Marshall, University of

Sheffield, UK

Reviewed by:

Pierre Bize, University of

Aberdeen, UK

Pete C. Trimmer, University of

Bristol, UK

Alexander Taylor Baugh,

Swarthmore College, USA

*Correspondence:

Sonja E. Koski, Centre of Excellence in Research on Intersubjectivity in

Interaction, University of Helsinki,

PO Box 4, Helsinki 00014, Finland

e-mail: sonja.koski@helsinki.fi
Personality is at the forefront of current behavioral ecological research. Most research concerns boldness, aggressiveness, activity, exploratory tendency, and sociability. However, many species may exhibit consistent variation in other traits, which the current research problematically misses. Exclusive adherence to the five traits ignores the possibility that other traits may be more consequential for a species and limits our understanding of the personality trait repertoire and the potentially complex associations among the usually sampled and other traits. Selecting personality traits based on species' ecology is crucial for understanding the causes and consequences of personality, and assessing a broader range of personality traits yields a better understanding of the trait associations. Studying the five traits has been useful in delineating research methods and aims, but it is time to broaden the personality horizon.

Keywords: personality, temperament, boldness, exploration, sociability

\section{INTRODUCTION: THE COMMONLY MEASURED ANIMAL PERSONALITY TRAITS}

Personality has emerged as one of the most important concepts in behavioral ecology in the past 10 years. Remarkably for such a young research field, initially divergent research lines and methods (Gosling, 2001; Sih et al., 2004; Réale et al., 2007) have converged, and there is now broad consensus about the definition of, relevant questions in, and methods to study animal personality (Réale and Dingemanse, 2012; but see Carter et al., 2013 for a thorough discussion on problems in the current personality research). The widely accepted definition of animal personality in the ecological literature is consistent individual differences in behavioral patterns. The relevant research questions of the day deal with explaining why behavioral plasticity is constrained, how individual differences in behavior are maintained, what explains consistent correlations among functionally distinct traits, and how personality affects ecological processes (Bergmüller and Taborsky, 2010; Réale et al., 2010; Sih et al., 2012; Wolf and Weissing, 2012). The assessment methods are similar across ecologically and evolutionarily scoped studies, relying mostly on a small set of experimental paradigms. However, there is a largely ignored, yet fundamental question that should be revisited: what behaviors are considered as personality traits? More specifically, it is clear that certain, frequently assessed personality traits such as boldness and aggressiveness are universal across species (Réale et al., 2007, 2010; Sih and Bell, 2008). But is there anything else out there?

This question is highly timely, as the corpus of personality studies increases and the aims have shifted from documentation to understanding the proximate causation and ultimate consequences of personality. To successfully reach those aims, we need a clear picture of what personality traits exist across species. Yet, the overwhelming majority of animal personality studies focuses on a small set of traits: boldness, exploration tendency, aggressiveness, activity, and sociability [reviews Mather and Logue, 2013 (invertebrates); Conrad et al., 2011; Mittelbach et al., 2014 (fish); van Oers and Naguib, 2013 (birds)], with the exception of studies applying an approach based on human personality psychology (e.g., Weiss et al., 2011).

These five traits were first listed in the influential review by Réale et al. (2007; cf. Gosling, 2001). While the authors discussed the five traits as a simplified working tool, in practice they have become the blueprint for animal personality studies. Personality is operationalized by assessing behavioral responses in a particular context, assumed to reflect a particular trait. The targeted traits are usually one or two of the five, with sociability receiving less research attention than the other four traits. These behaviors are expressed especially in contexts of habitat exploitation and defense, whilst behavior in other contexts such as mate selection, parental care, and affiliative social interactions are less often addressed (but see e.g., Schuett et al., 2010; Seyfarth et al., 2012). This approach is practical, fast, and allows broad comparability across species, but may impose significant limitations on where we look for personality in the first place. Although several researchers have highlighted issues in the current research regarding the use of particular experimental assays to capture the targeted traits (e.g., Carter et al., 2013) and statistical tools to deal with the obtained data (e.g., Dingemanse et al., 2010; Dingemanse and Dochtermann, 2013; Baugh et al., 2014), the trait selection as a process has been practically ignored (but see Uher, 2008; Dall and Griffith, 2014). Therefore, in this paper I mainly focus on the step before the data are obtained: which traits are considered as personality traits in animals. I will discuss issues concerning methods of assessment and analysis when they are pertinent to the trait selection question. 


\section{WHY GO BEYOND THE FIVE TRAITS?}

There are three main problems with adhering exclusively to the five commonly measured traits. First, the most consequential personality traits for a species may not be among the commonly measured traits. Conceptually, any aspect of the behavioral phenotype of a species can be an aspect of its personality. Notwithstanding the differences in the concept of "trait" in the psychological and biological lingo (van Oers, 2008; ArayaAjoy and Dingemanse, 2014), any behavioral trait that meets the definition agrees with the biological concept of personality. Therefore, a priori selection of traits that will be subjected to the assessment of repeatability is an important step in personality research that should be based on well-founded reasoning. Ideally, research should target traits that are ecologically most relevant to the study species (Dall and Griffith, 2014). This requires knowledge of the species' ecology and behavioral repertoire. In contrast, choosing the assessed trait simply by "tokenism," assumed relevance because the trait is relevant or commonly measured in another species, ignores possibly important differences in the trait relevance across species. For example, for a species that lives in a stable social group, personality traits that influence fitness the most are probably in the realm of social behavior, such as the tendency to initiate friendly body contacts with others (chacma baboons Papio hamadryas ursinus: Seyfarth et al., 2012), whilst for a solitary species predator avoidance, behaviors in habitat defense or exploitation contexts may be most consequential (e.g., hermit crab Pagurus bernhardus: Mowles et al., 2012).

Second, species may differ not just in the type of traits that have the highest relevance, but also in the number of them. It is conceivable that some taxa have a higher number of ecologically relevant personality traits than others, depending on the complexity of their ecological and social niche, simply because their daily life involves a broader range of behavioral traits in different contexts. Currently we have little understanding of personality traits beyond the five common ones across species, or what determines the breadth of personality trait "repertoire," and this will remain so if we keep assessing only the limited set of traits.

Third, personality traits are not expressed independently, but they form sets of consistently correlated traits (Sih and Bell, 2008; Dochtermann and Dingemanse, 2013). For example, aggressiveness and boldness show an among-individual correlation in many species, indicating that they form a functionally distinct unit. Indeed, every trait is expressed by a number of measurable behavioral responses in certain situations that are associated with or independent from responses in other situations, forming a hierarchical structure (Araya-Ajoy and Dingemanse, 2014). The causal mechanisms and the ultimate consequences of such trait associations are at the forefront of personality research. Yet, thus far most researchers sample trait associations only among a few traits, or even more narrowly between two traits, whilst the true structure of behavioral traits probably extends well beyond these. As selection targets phenotypes and behavioral phenotypes are the outcome of multiple, simultaneously affecting factors, including multiple personality traits, fitness consequences are dependent on the individual's whole personality profile (Dochtermann and Dingemanse, 2013; Weiss and Adams, 2013). A systematic assessment of the trait organization at higher and lower hierarchical levels would help unravel the evolutionary consequences of personality in a much more comprehensive way than thus far is achieved.

An additional concern in adherence to a small number of traits relates to the validity of the experimental assays. When the goal is to assess a particular, commonly assessed trait, researchers tend to choose an assay that is used previously on another species. However, the behavioral outcomes may not reflect the intended traits. The standard experimental paradigms such as open field (Walsh and Cummins, 1976), or novel object (e.g., Kurvers et al., 2009) may yield variables reflecting several traits, and different paradigms targeted to measure the same trait may actually measure different traits (Carter et al., 2013). For example, Carter et al. (2012) showed that two commonly used assays to target boldness, the predator-model and novel-food assay, did not result in similar responses in baboons. Instead, responses in one context agreed with the concept of boldness, while responses in the other reflected anxiety. Similarly, Beckmann and Biro (2013) showed that in two species of damselfish (Pomacentrus wardi and P. amboinensis), latency to emerge from a shelter in a novel environment does not correlate with the emergence behavior in a home tank. When the study is designed to target only one trait with one assay, the confounding effects of other traits are missed, along with the assessment of assay's validity (Burns, 2008). In contrast, an initial goal to capture a broad range of traits with multiple assays increases the certainty of using appropriate assays and the awareness of what is being measured.

\section{SUPPORT FOR BROADENING THE SCOPE BEYOND THE FIVE TRAITS}

Research on consistent individual differences in maternal behavior supports the benefits of assessing traits beyond the common ones. Females of many species exhibit consistent differences in their maternal behavior [e.g., laboratory rodents (Mus musculus, Rattus rattus): Francis et al., 2000; guinea pigs (Cavia aperea): Albers et al., 1999; rhesus macaques: (Macaca mulatta) Maestripieri, 2001; chimpanzees (Pan troglodytes): de Lathouwers and van Elsacker, 2004]. Differences in such "maternal styles" have significant consequences on the offspring development and later adult behavior. For example, high levels of grooming by a rodent mother increases male offspring's exploratory behavior and cognitive capacities (Curley and Branchi, 2013), and a rejective mothering style leads to earlier offspring independence in Japanese macaques (Macaca fuscata; Bardi and Huffman, 2002), possibly increasing offspring mortality (Fairbanks, 1996). The connection between maternal behavior and (other) personality traits has long been hypothesized (e.g., Fairbanks, 2005; Réale et al., 2007; Maestripieri, 2011) but rarely studied in non-humans [but see cichlids (Cichlasoma nigrofasciatum): Budaev et al., 1999; rhesus macaques: Maestripieri, 1993]. Consistent differences in maternal styles could be considered in relation to social behavior toward adult conspecifics, as well as e.g., general activity, reactivity, and aggression to understand whether and how parental behavior is dependent on other aspects of personality and how this varies across taxa.

Another example of an interesting personality trait comes from water striders (Aquarius remigis) that exhibit individual 
variation in activity and aggressiveness. Overtly aggressive males have poor "social skill" in the sense of being unable to adjust mating behavior according to the target identity, leading to decreased mating success (Sih et al., 2014). Whilst in water striders social skill is captured by measuring aggressiveness, it may reflect a more general social competence (Taborsky and Oliveira, 2012).

Some studies have also called attention to cooperation (meerkats Suricata suricatta English et al., 2010; cichlid Neolamprologus pulcher: Schürch and Heg, 2010), choosiness (McNamara et al., 2008; Sih and Del Giudice, 2012), and problem-solving (great tit Parus major: Cole and Quinn, 2012) as meaningful personality traits. Individual cooperativeness in cichlids, for example, is negatively related to dispersal and adult clutch size (Schürch and Heg, 2010), and may affect group composition (Schurch et al., 2010). Problem-solving ability in great tits is negatively related to competitive ability and exploration, suggesting trade-offs in competitive strategies (Cole and Quinn, 2012).

Many of the aforementioned advances concern social behavior, reflecting its importance in biologically significant contexts including partner choice, mating, parenting, intra,- and intergroup competition, and cooperation. Importantly, extending personality to social behaviors does not apply only to highly social species. Social competence and choosiness apply potentially to any sexually reproducing species, because they influence behavior in mate choice, offspring care, resource defense, and exploitation (Sih, 2012; Taborsky and Oliveira, 2012). Parental behavior is not limited to mammals, but present also in birds, many species of fish (Crawford and Balon, 1996), and some amphibians (e.g., Eleutherodactylus cooki: Burrowes, 2000), reptiles (e.g., Egernia saxatilis: O'Connor and Shine, 2004), and invertebrates (Trumbo, 1996), calling for research on individual variation in parental investment (Westneat et al., 2011). Similarly, variation in cooperativeness may occur in a range of species from aggregating anemones and schooling fish to more intensively social species such as eusocial insects and cooperatively breeding birds and mammals (Bergmüller et al., 2010).

Sampling additional traits helps to obtain information of the dependencies among traits. In the psychology-based animal personality research simultaneous assessment of multiple traits and their hierarchical structure is emphasized (Gosling, 2001; Uher, 2008). Human personality theory conceptualizes personality as a psychological construct consisting of several independent main dimensions, each of which includes several correlated facets (Digman, 1990). Research applying the human personality theory to animals has revealed interesting results on the evolutionary history of personality trait hierarchy (Weiss et al., 2011), and the consequences of personality on the animals' subjective well being (Weiss et al., 2012). In line with this view, recent literature in behavioral ecology has highlighted the hierarchical trait organization (Dochtermann and Dingemanse, 2013; Araya-Ajoy and Dingemanse, 2014). Behavioral studies of primates have addressed the multi-dimensionality of personality, showing that primate personality comprises several social and non-social dimensions, each including several correlated behaviors (Konečná et al., 2008; Koski, 2011; Massen et al., 2013; Neumann et al., 2013). For example, anxiety, boldness, and aggressiveness are independent in crested macaques (Macaca nigra: Neumann et al., 2013), which is surprising considering the vast evidence of their association in many species (Koolhaas et al., 1999). In addition, the species exhibits two independent dimensions of social behavior. Behavioral multi-trait research in primates has also revealed for instance that social bonding of chimpanzees is dependent on partners' similarity in boldness and gregariousness (Massen and Koski, 2014), and that a friendly behavioral type increases chacma baboons' fitness independent of rank (Seyfarth et al., 2012). Unfortunately, comparable studies are scarce in non-primate species (but see dogs: Svartberg and Forkman, 2002), including the much-studied model species, such as great tits and guppies. Therefore, the details of trait organization and its consequences in most species are yet to be discovered.

\section{HOW TO GO ABOUT SAMPLING "OTHER" TRAITS?}

I have highlighted the need to broaden the scope of animal personality research to include traits that are not commonly assessed across species. Here, I will reiterate the argument with a brief, summarizing guide:

(1) Identify the relevant contexts and the behaviors exhibited in them based on the study question. As many have argued before (e.g., Dall and Griffith, 2014), personality research can and should move toward theory-driven questions. Hence, selecting the relevant personality traits sampled in a population should be based on the research question and the species ecology, because only then can we make informed predictions about the causes and consequences of the traits, and use ecologically valid methods to assess them.

Many current behavioral ecology studies focus on the consequences of personality. As the range of potential consequences is vast (cf. Wolf and Weissing, 2012), research should target traits that influence the particular causal relationship assessed. The consequences-were they at individual, population, or evolutionary levels - are affected simultaneously by several traits. For example, when addressing personality's effect on disease spread, all traits that influence an individual's proximity with others may play a role, including boldness, aggressive and affiliative tendencies, association rate, duration, density, and assortment (Pike et al., 2008; Krause et al., 2010; Sih, 2012). As it is not feasible to address all in one study, considered prioritization of the sampled traits is imperative. In proximate questions, the focus is on the developmental processes, and genetic and neuroendocrine mechanisms underlying personality. Usually the predictions concern only one or two traits (e.g., dopamine receptor gene and neophilia: Bailey et al., 2007; vasopressin receptor gene and pair-bonding: Bradley and Lawler, 2011). However, the relationships may in reality be much more complex (cf. HPA-axis and the neural substrates: Koolhaas et al., 2010), again illustrating the need for an informed consideration and selection of the relevant aspects.

(2) Consider whether sampling additional traits is informative. Trait associations are likely to go beyond the commonly assessed correlations and vary across taxa. Obviously, it is 
not possible or necessary to understand all trait dependencies in any absolute sense. In functional research, an obtainable goal could be to examine first the traits that are identified as the most relevant ones in the step 1, and in subsequent studies examine the role of other factors. Niche complexity may be a useful concept in formulating predictions about the trait structure. As the species' social and/or ecological niche complexity increases, the trait repertoire and the structural complexity are also expected to increase, simply because the species encounters a higher number of relevant contexts requiring many different behaviors.

(3) Know what you are measuring. Choosing the appropriate assays and labeling traits correctly are crucial for meeting the goals set in the first two steps. Both construct validity (i.e., that the assay is measuring behavior it is supposed to measure: Cronbach and Meehl, 1955), and ecological validity (i.e., that the test design and the measured behaviors are ecologically relevant for the species: Réale et al., 2007; Beckmann and Biro, 2013) of the methods must be emphasized, because the results are meaningfully interpretable only if the methods are valid (Burns, 2008; Uher, 2008; Beckmann and Biro, 2013; Carter et al., 2013). Moreover, labeling measured traits appropriately is important for understanding what the responses tell us. Careless trait labeling may lead to jingle-jangle fallacy (i.e., distinct traits are labeled as the same, or a trait is given several names: Thorndike, 1903; Kelley, 1927; cf. Gosling, 2001). Studies that have assessed sociability illustrate potential labeling problems. "Sociability" as a label has been applied to a wide variety of behaviors: propensity to approach a conspecific (cowbirds Molothrus ater ater: Kohn et al., 2013), time spent in a hiding place in presence of conspecific olfactory cues (common lizards Lacerta vivipara: Cote et al., 2008), tendency to affiliate with group members (rhesus macaques: Capitanio et al., 2008 and chacma baboons: Seyfarth et al., 2012), and the number of near neighbors and grooming frequency (chimpanzees: Koski, 2011). It is unclear whether such different expressions of social preference all reflect a shared latent trait "sociability" or whether there are actually multiple functionally separate personality traits to social preferences.

To conclude, there are problems in adhering only to the commonly measured personality traits and gains in sampling additional ones. I have discussed some of the advances made by research on additional personality traits especially in social behavior, and called attention to the importance of understanding traits structures. I hope to encourage researchers to broaden the personality research horizon.

\section{ACKNOWLEDGMENTS}

I thank Thomas Bugnyar, Judith Burkart, AJ Carter, Jorg Massen, Carel van Schaik, Alex Weiss, and three reviewers for inspiring insights and very constructive comments on earlier versions of this manuscript. This research was supported by Ella \& Georg Ernrooth Foundation, Schultz Foundation, and University of Zürich's Anthropological Institute.

\section{REFERENCES}

Albers, P. C. H., Timmermans, P. J. A., and Vossen, J. H. M. (1999). Evidence for the existence of mothering styles in guinea pigs (Cavia aperea f. porcellus). Behaviour 136, 469-479. doi: 10.1163/156853999501423

Araya-Ajoy, Y. G., and Dingemanse, N. J. (2014). Characterizing behavioural "characters": an evolutionary framework. Proc. R. Soc. B 281:20132645. doi: 10.1098/rspb.2013.2645

Bailey, J. N., Breidenthal, S. E., Jorgensen, M. J., McCracken, J. T., and Fairbanks, L. A. (2007). The association of DRD4 and novelty seeking is found in a nonhuman primate model. Psychatric. Gen. 17, 23-27. doi: 10.1097/YPG.0b013e32801140f2

Bardi, M., and Huffman, M. A. (2002). Effects of maternal style on infant behavior in Japanese macaques (Macaca fuscata). Dev. Psychobiol. 41, 364-372. doi: 10.1002/dev.10065

Baugh, A. T., van Oers, K., Dingemanse, N. J., and Hau, M. (2014). Baseline and stress-induced glucocorticoid concentrations are not repeatable but covary within individual great tits (Parus major). Gen. Comp. Endocrinol. 208, 154-163. doi: 10.1016/j.ygcen.2014.08.014

Beckmann, C., and Biro, P. A. (2013). On the validity of a single (boldness) assay in personality research. Ethology 119, 937-947. doi: 10.1111/eth.12137

Bergmüller, R., Schurch, R., and Hamilton, I. M. (2010). Evolutionary causes and consequences of consistent individual variation in cooperative behaviour. Philos. Trans. R Soc. B 365, 2751-2764. doi: 10.1098/rstb. 2010.0124

Bergmüller, R., and Taborsky, M. (2010). Animal personality due to social niche specialisation. Trends Ecol. Evol. 25, 504-511. doi: 10.1016/j.tree.2010.06.012

Bradley, B. J., and Lawler, R. R. (2011). Linking genotypes, phenotypes, and fitness in wild primate populations. Evol. Anthropol. 20, 104-119. doi: 10.1002/evan.20306

Budaev, S. V., Zworykin, D. D., and Mochek, A. D. (1999). Individual differences in parental care and behaviour profile in the convict cichlid: a correlation study. Anim. Behav. 58, 195-202. doi: 10.1006/anbe.1999.1124

Burns, J. G. (2008). The validity of three tests of temperament in guppies (Poecilia reticulata). J. Comp. Psychol. 122, 344-356. doi: 10.1037/0735-7036.122.4.344

Burrowes, P. A. (2000). Parental care and sexual selection in the Puerto Rican cave dwelling frog Eleutherodactylus cooki. Herpetologica 56, 375-386.

Capitanio, J. P., Abel, K., Mendoza, S. P., Blozis, S. A., McChesney, M. B., Cole, S. W., et al. (2008). Personality and serotonin transporter genotype interact with social context to affect immunity and viral set-point in simian immunodeficiency virus disease. Brain Behav. Immun. 22, 676-689. doi: 10.1016/j.bbi.2007. 05.006

Carter, A. J., Feeney, W. E., Marshall, H. H., Cowlishaw, G., and Heinsohn, R. (2013). Animal personality: what are behavioural ecologists measuring? Biol. Rev. 88, 465-475. doi: 10.1111/brv.12007

Carter, A. J., Marshall, H. H., Heinsohn, R., and Cowlishaw, G. (2012). How not to measure boldness: novel object and antipredator responses are not the same in wild baboons. Anim. Behav. 84, 603-609. doi: 10.1016/j.anbehav.2012.06.015

Cole, E. F., and Quinn, J. L. (2012). Personality and problem-solving performance explain competitive ability in the wild. Proc. R. Soc. B 279, 1168-1175. doi: 10.1098/rspb.2011.1539

Conrad, J. L., Weinersmith, K. L., Brodin, T., Saltz, J. B., and Sih, A. (2011). Behavioural syndromes in fishes: a review with implications for ecology and fisheries management. J. Fish Biol. 78, 395-435. doi: 10.1111/j.10958649.2010.02874.x

Cote, J., Dreiss, A., and Clobert, J. (2008). Social personality trait and fitness. Proc. R. Soc. B 275, 2851-2858. doi: 10.1098/rspb.2008.0783

Crawford, S. S., and Balon, E. K. (1996). "Cause and effect of parental care in fishes: and epigenetic perspective," in Parental Care. Evolution, Mechanisms, and Adaptive Significance. Advances in the Study of Behavior, Vol. 25, eds J. S Rosenblatt and C. T. Snowdon (San Diego, CA: Academic Press), 53-107.

Cronbach, L. J., and Meehl, P. E. (1955). Construct validity in psychological tests. Psychol. Bull. 52, 281-302. doi: 10.1037/h0040957

Curley, J. P., and Branchi, I. (2013). "Ontogeny of stable individual differences: gene, environment, and epigenetic mechanisms," in Animal Personalities. Behaviour, Physiology, and Evolution, eds C. Carere and D. Maestripieri (London: University of Chicago Press), 279-316.

Dall, S. R., and Griffith, S. C. (2014). An empiricist guide to animal personality variation in ecology and evolution. Front. Ecol. Evol. 2:3. doi: $10.3389 /$ fevo. 2014.00003 
de Lathouwers, M., and van Elsacker, L. (2004). Comparing maternal styles in bonobos (Pan paniscus) and chimpanzees (Pan troglodytes). Am. J. Primatol. 64, 411-423. doi: 10.1002/ajp.20089

Digman, J. M. (1990). Personality structure: emergence of the five-factor model. Annu. Rev. Psychol. 41, 417-440. doi: 10.1146/annurev.ps.41.020190.002221

Dingemanse, N. J., and Dochtermann, N. A. (2013). Quantifying individual variation in behaviour: mixed-effect modelling approaches. J. Anim. Ecol. 82, 39-54. doi: $10.1111 / 1365-2656.12013$

Dingemanse, N. J., Dochtermann, N., and Wright, J. (2010). A method for exploring the structure of behavioural syndromes to allow formal comparison within and between data sets. Anim. Behav. 79, 439-450. doi: 10.1016/j.anbehav.2009.11.024

Dochtermann, N. A., and Dingemanse, N. J. (2013). Behavioral syndromes as evolutionary constraints. Behav. Ecol. 24, 806-811. doi: 10.1093/beheco/art002

English, S., Nakagawa, S., and Clutton-Brock, T. H. (2010). Consistent individual differences in cooperative behaviour in meerkats (Suricata suricatta). J. Evol. Biol. 23, 1597-1604. doi: 10.1111/j.1420-9101.2010.02025.x

Fairbanks, L. A. (1996). Individual differences in maternal style: causes and consequences for mothers and offspring. Adv. Study Behav. 25, 579-611. doi: 10.1016/S0065-3454(08)60343-5

Fairbanks, L. A. (2005). "Parenting," in Primate Psychology, ed D. Maestripieri (Cambridge, MA: Harvard University Press), 144-170.

Francis, D. D., Champagne, F. A., and Meaney, M. J. (2000). Variations in maternal behaviour are associated with differences in oxytocin receptor levels in the rat. J. Neuroendocrinol. 12, 1145-1148. doi: 10.1046/j.1365-2826.2000.00599.x

Gosling, S. D. (2001). From mice to men: what can we learn about personality from animal research? Psychol. Bull. 127, 45-86. doi: 10.1037/0033-2909.127.1.45

Kelley, G. A. (1927). Interpretation of Educational Measurements. Yonkers, NY: World Book.

Kohn, G. M., Kohn, G. M., King, A. P., Dohme, R., Meredith, G. R., and West, M. J. (2013). In the company of cowbirds, Molothrus ater ater: robust patterns of sociability predict reproductive performance. J. Comp. Psychol. 127, 40-48. doi: 10.1037/a0029681

Konečná, M., Lhota, S., Weiss, A., Urbánek, T., Adamová, T., and Pluháček, J. (2008). Personality in free-ranging Hanuman langur (Semnopithecus entellus) males: subjective ratings and recorded behavior. J. Comp. Psychol. 122, 379-389. doi: 10.1037/a0012625

Koolhaas, J. M., de Boer, S. F., Coppens, C. M., and Buwalda, B. (2010) Neuroendocrinology of coping styles: towards understanding the biology of individual variation. Front. Neuroendocrinol. 31, 307-321. doi: 10.1016/j.yfrne.2010.04.001

Koolhaas, J. M., Korte, S. M., de Boer, S. F., Van Der Vegt, B. J., Van Reenen, C. G., Hopster, H., et al. (1999). Coping styles in animals: current status in behavior and stress-physiology. Neurosci. Biobehav. Rev. 23, 925-935. doi: 10.1016/S01497634(99)00026-3

Koski, S. E. (2011). Social personality traits in chimpanzees: temporal stability and structure of behaviourally assessed personality traits in three captive populations. Behav. Ecol. Sociobiol. 65, 2161-2174. doi: 10.1007/s00265-011-1224-0

Krause, J., James, R., and Croft, D. P. (2010). Personality in the context of social networks. Philos. Trans. R. Soc. B 365, 4099-4106. doi: 10.1098/rstb. 2010.0216

Kurvers, R. H. J. M., Eijkelenkamp, B., van Oers, K., van Lith, B., Van Wieren, S. E., Ydenberg, R. C., et al. (2009). Personality differences explain leadership in barnacle geese. Anim. Behav. 78, 447-453. doi: 10.1016/j.anbehav.2009.06.002

Maestripieri, D. (1993). Maternal anxiety in rhesus macaques (Macaca mulatta) II. Emotional bases of individual differences in mothering style. Ethology 95 32-42. doi: 10.1111/j.1439-0310.1993.tb00454.x

Maestripieri, D. (2001). Intraspecific variability in parenting styles of rhesus macaques (Macaca mulatta): the role of the social environment. Ethology 107, 237-248. doi: 10.1046/j.1439-0310.2001.00661.x

Maestripieri, D. (2011). Emotions, stress, and maternal motivation in primates. Am. J. Primatol. 73, 516-529. doi: 10.1002/ajp.20882

Massen, J. J. M., Antonides, A., Arnold, A. M. K., Bionda, T., and Koski, S. E. (2013). A behavioral view on chimpanzee personality: exploration tendency, persistence, boldness, and tool-orientation measured with group experiments. Am. J. Primatol. 75, 947-958. doi: 10.1002/ajp.22159

Massen, J. J. M., and Koski, S. E. (2014). Chimps of a feather sit together: chimpanzee friendships are based on homophily in personality. Evol. Hum. Behav. 35, 1-8. doi: 10.1016/j.evolhumbehav.2013.08.008
Mather, J. A., and Logue, D. M. (2013). "The bold and the spineless. Insect personalities," in Animal Personalities. Behaviour, Physiology, and Evolution, eds C. Carere and D. Maestripieri (London: University Chicago Press), 13-35

McNamara, J. M., Barta, Z., Fromhage, L., and Houston, A. I. (2008). The coevolution of choosiness and cooperation. Nature 451, 189-192. doi: 10.1038 /nature06455

Mittelbach, G. G., Ballew, N. G., Kjelvik, M. K., and Fraser, D. (2014). Fish behavioral types and their ecological consequences. Can. J. Fish. Aquat. Sci. 71, 927-944. doi: 10.1139/cjfas-2013-0558

Mowles, S. L., Cotton, P. A., and Briffa, M. (2012). Consistent crustaceans: the identification of stable behavioural syndromes in hermit crabs. Behav. Ecol. Sociobiol. 66, 1087-1094. doi: 10.1007/s00265-012-1359-7

Neumann, C., Agil, M., Widdig, A., and Engelhardt, A. (2013). Personality of wild male Crested Macaques (Macaca nigra). PLoS ONE 8:e69383. doi: 10.1371/journal.pone.0069383

O'Connor, D. E., and Shine, R. (2004). Parental care protects against infanticide in the lizard Egernia saxatilis (Scincidae). Anim. Behav. 68, 1361-1369. doi: 10.1016/j.anbehav.2004.02.014

Pike, T. W., Samanta, M., Lindström, J., and Royle, N. J. (2008). Behavioural phenotype affects social interactions in an animal network. Proc. R. Soc. B. 275 2515-2520. doi: 10.1098/rspb.2008.0744

Réale, D., and Dingemanse, N. J. (2012). Personality and Temperament. Chichester: eLS. John Wiley \& sons, Ltd.

Réale, D., Dingemanse, N. J., Kazem, A. J. N., and Wright, J. (2010). Evolutionary and ecological approaches to the study of personality. Philos. Trans. R. Soc. B 365, 3937-3946. doi: 10.1098/rstb.2010.0222

Réale, D., Reader, S. M., Sol, D., McDougall, P. T., and Dingemanse, N. J. (2007). Integrating animal temperament within ecology and evolution. Biol. Rev. 82, 291-318. doi: 10.1111/j.1469-185X.2007.00010.x

Schuett, W., Tregenza, T., and Dall, S. R. X. (2010). Sexual selection and animal personality. Biol. Rev. 85, 217-246. doi: 10.1111/j.1469-185X.2009. 00101.x

Schürch, R., and Heg, D. (2010). Variation in helper type affects group stability and reproductive decisions in a cooperative breeder. Ethology 116, 257-269. doi: 10.1111/j.1439-0310.2009.01738.x

Schurch, R., Rothenberger, S., and Heg, D. (2010). The building-up of social relationships: behavioural types, social networks and cooperative breeding in a cichlid. Philos. Trans. R. Soc. B 365, 4089-4098. doi: 10.1098/rstb. 2010.0177

Seyfarth, R. M., Silk, J. B., and Cheney, D. L. (2012). Variation in personality and fitness in wild female baboons. Proc. Natl. Acad. Sci. U.S.A. 109, 16980-16985. doi: 10.1073/pnas.1210780109

Sih, A. (2012). "Behavioral syndromes: a behavioral ecologist's view on the evolutionary and ecological implications of animal personalities," in Personality and Temperament in Nonhuman Primates, eds A. Weiss, J. E. King, J. S. Rosenblatt, and L. Murray (New York, NY: Springer), 313-336.

Sih, A., and Bell, A. M. (2008). Insights for behavioral ecology from behavioral syndromes. Adv. Study Behav. 38, 227-281. doi: 10.1016/S0065-3454(08) 00005-3

Sih, A., Bell, A. M., Johnson, J. C., and Ziemba, R. E. (2004). Behavioural syndromes: an integrative overview. Q. J. Biol. 79, 241-277. doi: 10.1086/ 422893

Sih, A., Chang, A. T., and Wey, T. W. (2014). Effects of behavioural type, social skill and the social environment on male mating success in water striders. Anim. Behav. 94, 9-17. doi: 10.1016/j.anbehav.2014.05.010

Sih, A., Cote, J., Evans, M., Fogarty, S., and Pruitt, J. (2012). Ecological implications of behavioural syndromes. Ecol. Lett. 15, 278-289. doi: 10.1111/j.14610248.2011.01731.x

Sih, A., and Del Giudice, M. (2012). Linking behavioural syndromes and cognition: a behavioural ecology perspective. Philos. Trans. R. Soc. B 367, 2762-2772. doi: 10.1098/rstb.2012.0216

Svartberg, K., and Forkman, B. (2002). Personality traits in the domestic dog (Canis familiaris). Appl. Anim. Behav. Sci 79, 133-155. doi: 10.1016/S0168 1591(02)00121-1

Taborsky, B., and Oliveira, R. F. (2012). Social competence: an evolutionary approach. Trends Ecol. Evol. 27, 679-688. doi: 10.1016/j.tree.2012.09.003

Thorndike, E. L. (1903). Notes on Child Study, 2nd Edn. New York, NY: Macmillan. Trumbo, S. T. (1996). "Parental care among invertebrates," in Parental Care. Evolution, Mechanisms, and Adaptive Significance. Advances in the Study of 
Behavior, Vol. 25, eds J. S. Rosenblatt and C. T. Snowdon (San Diego, CA: Academic Press), 3-50.

Uher, J. (2008). Comparative personality research: methodological approaches. Eur. J. Pers. 22, 427-455. doi: 10.1002/per.680

van Oers, K. (2008). Animal personality, behaviours or traits: what are we measuring? Eur. J. Pers. 22, 470-472.

van Oers, K., and Naguib, M. (2013). "Avian personality”, in Animal Personalities. Behaviour, Physiology, and Evolution, eds C. Carere and D. Maestripieri (London: University Chicago Press), 66-95.

Walsh, R. N., and Cummins, R. A. (1976). The open field test: a critical review. Psychol. Bull. 83, 482-504. doi: 10.1037/0033-2909.83.3.482

Weiss, A., and Adams, M. J. (2013). "Differential behavioral ecology: the structure, life history and evolution of primate personality," in Animal Personalities. Behaviour, Physiology, and Evolution, eds C. Carere and D. Maestripieri (London: University Chicago Press), 96-123.

Weiss, A., Adams, M. J., Widdig, A., and Gerald, M. S. (2011). Rhesus macaques (Macaca mulatta) as living fossils of hominoid personality and subjective wellbeing. J. Comp. Psychol. 125, 72-83. doi: 10.1037/a0021187

Weiss, A., King, J. E., Inoue-Murayama, M., Matsuzawa, T., and Oswald, A. J. (2012). Evidence for a "midlife crisis" in great apes consistent with the Ushape in human well-being. Proc. Natl. Acad. Sci. U.S.A. 109, 19949-19952 doi: $10.1073 /$ pnas. 1212592109
Westneat, D. F., Hatch, M. I., Wetzel, D. P., and Ensminger, A. L. (2011). Individual variation in parental care reaction norms: integration of personality and plasticity. Am. Nat. 178, 652-667. doi: 10.1086/662173

Wolf, M., and Weissing, F. J. (2012). Animal personalities: consequences for ecology and evolution. Trends Ecol. Evol. 27, 452-461. doi: 10.1016/j.tree.2012. 05.001

Conflict of Interest Statement: The author declares that the research was conducted in the absence of any commercial or financial relationships that could be construed as a potential conflict of interest.

Received: 30 July 2014; accepted: 08 October 2014; published online: 28 October 2014 Citation: Koski SE (2014) Broader horizons for animal personality research. Front. Ecol. Evol. 2:70. doi: 10.3389/fevo.2014.00070

This article was submitted to Behavioral and Evolutionary Ecology, a section of the journal Frontiers in Ecology and Evolution.

Copyright (c) 2014 Koski. This is an open-access article distributed under the terms of the Creative Commons Attribution License (CC BY). The use, distribution or reproduction in other forums is permitted, provided the original author(s) or licensor are credited and that the original publication in this journal is cited, in accordance with accepted academic practice. No use, distribution or reproduction is permitted which does not comply with these terms. 